\title{
Neurotrophin-3 Administration Attenuates Deficits of Pyridoxine-Induced Large-Fiber Sensory Neuropathy
}

\author{
Maureen E. Helgren, Kenneth D. Cliffer, Kim Torrento, Chris Cavnor, Rory Curtis, Peter S. DiStefano, \\ Stanley J. Wiegand, and Ronald M. Lindsay
}

Regeneron Pharmaceuticals, Inc., Tarrytown, New York 10591-6707

Chronic treatment of adult rats for 2-3 weeks with high doses of pyridoxine (vitamin $B_{6}$ ) produced a profound proprioceptive loss, similar to that found in humans overdosed with this vitamin or treated with the chemotherapeutic agent cisplatin. Pyridoxine toxicity was manifest as deficits in simple and precise locomotion and sensory nerve function and as degeneration of large-diameter/large-fiber spinal sensory neurons. As assessed quantitatively in a beam-walking task and by EMG recording of $\mathrm{H}$ waves evoked by peripheral nerve stimulation, coadministration of the neurotrophic factor neurotrophin-3 (NT-3; 5-20 mg • $\mathrm{kg}^{-1} \cdot \mathrm{d}^{-1}$, s.c.) during chronic pyridoxine treatment largely attenuated the behavioral and electrophysiological sequelae associated with pyridoxine toxicity. Furthermore, NT-3 administration prevented degeneration of sensory fibers in the dorsal column of the spinal cord. These data are consistent with the evidence that NT-3 is a target-derived neurotrophic factor for muscle sensory afferents and suggest that pharmacological doses of NT-3 may be beneficial in the treatment of large-fiber sensory neuropathies.

Key words: NT-3; sensory neuropathy; proprioception; DRG; pyridoxine; sensory-motor function
There is now strong evidence that neurotrophin-3 (NT-3) functions as a target-derived factor for proprioceptive neurons. Like brain-derived neurotrophic factor (BDNF) but unlike nerve growth factor (NGF), NT-3 promotes the survival of sensory neurons of neural placode-derived cranial ganglia (Lindsay et al., 1985; Davies et al., 1987). In contrast, all three neurotrophins produce varying degrees of neurite outgrowth from neural crestderived dorsal root ganglion (DRG) neurons (Maisonpierre et al., 1990). Both in explant and in dissociated neuron-enriched cultures, the effects of NT-3 on neurite outgrowth and survival were found to be greater for DRG taken from the cervical or lumbar enlargements than for DRG from sacral or thoracic regions (Hory-Lee et al., 1993). Back-labeling of sensory afferents to either skin or muscle in ovo before culturing has confirmed greater survival-promoting effects of NT-3 on muscle afferents than on skin afferents.

Proprioceptive neurons are among the largest neurons in the DRG. Studies of receptor-mediated retrograde axonal transport of the neurotrophins in the PNS of the adult rat have demonstrated that radiolabeled NT-3 accumulates predominantly in large DRG neurons. In contrast, radiolabeled NGF accumulates mostly in small DRG neurons, and BDNF accumulates in a fairly broad spectrum of small- to large-diameter neurons (DiStefano et al., 1992). Confirming the specificity of NT-3 for large spinal sensory neurons, in situ hybridization studies have localized expression of TrkC, the NT-3 high-affinity receptor (for review of

Received June 27, 1996; revised Oct. 18, 1996; accepted Oct. 22, 1996.

We thank Art Asbury for his guidance in selecting this model of peripheral neuropathy, Beth Friedman for many insightful discussions, Floyd Thompson for advice on physiological recordings, and Joanne Conover and Debra Compton for their assistance with the in situ hybridization studies. We also thank Dr. Len S. Schleifer and Regeneron colleagues for their enthusiastic support.

Correspondence should be addressed to Dr. Ronald M. Lindsay, Regeneron Pharmaceuticals, Inc., 777 Old Saw Mill River Road, Tarrytown, NY 10591.

Dr. Helgren's present address: Quinnipiac College, Department of Physical Therapy, Hamden CT 06518.

Copyright (C) 1996 Society for Neuroscience $0270-6474 / 96 / 170372-11 \$ 05.00 / 0$ the Trk family of neurotrophin receptors, see Glass and Yancopoulos, 1993), predominantly to large-diameter DRG neurons (McMahon et al., 1994).

Consistent with a role for NT-3 as a target-derived factor for muscle afferents, NT-3 mRNA is expressed in muscle spindles (Copray and Brouwer, 1994). In addition, mice that lack NT-3 expression as a result of a targeted null mutation (Ernfors et al., 1994) or developing chick embryos exposed to NT-3-neutralizing antibodies (Gaese et al., 1994) show a large decrease in the number of neurons in lumbar DRG. Strikingly, muscle spindles are totally absent in newborn mice lacking NT-3 expression (Ernfors et al., 1994).

Peripheral neuropathies encompass functional deficits in motor, sensory, and sympathetic neurons. Impairment in sensory function may involve mixed modalities, producing multiple symptoms (as in diabetic neuropathy) in which damage may occur to all classes of sensory neurons. In contrast, a specific large-fiber neuropathy, manifest as a severe loss of proprioceptive function, is encountered clinically after vitamin $\mathrm{B}_{6}$ (pyridoxine) intoxication (Schaumburg et al., 1983; Albin et al., 1987) or, more commonly, as a consequence of treatment with the chemotherapeutic drug cisplatin (Hamers et al., 1991; Krarup-Hansen et al., 1993). The possibility that neurotrophic factors may have utility for treatment of neurological insults, the specificity of NT-3 for proprioceptive neurons, and the availability of agents that are selectively toxic to proprioceptive neurons prompted us to explore the potential efficacy of NT-3 on a large-fiber neuropathy produced by chronic pyridoxine treatment of adult rats. Pyridoxine was selected as the neurotoxic agent in this study because it produces specific, marked impairment of proprioceptive function without producing profound systemic toxicity.

\section{MATERIALS AND METHODS}

Experiments were conducted on young adult female Sprague Dawley rats (200-250 gm). Animals were housed 2 animals/cage, given standard rat chow (Purina) ad libitum, and maintained on a $12 \mathrm{hr}$ light/dark cycle. All 
procedures were approved by an Institutional Animal Care and Use Committee according to National Institutes of Health guidelines.

\section{In situ hybridization}

Anesthetized normal control animals $(127-170 \mathrm{mg} / \mathrm{kg}$ chloral hydrate, $26-36 \mathrm{mg} / \mathrm{kg}$ pentobarbital) were exsanguinated, and the lumbar DRG were rapidly dissected and frozen in isopentene cooled with liquid nitrogen. The L4 and L5 fresh frozen DRG were sectioned at $10 \mu \mathrm{m}$ and thaw-mounted onto poly-lysine-coated slides. An $800 \mathrm{bp}$ cDNA fragment encoding the kinase domain for TrkC was subcloned into Bluescript $(\mathrm{KS}+) .{ }^{35} \mathrm{~S}$-radiolabeled antisense or sense strand probes were transcribed off linearized plasmids using a transcription kit (Promega, Madison, WI). In situ hybridization was performed as described previously (Friedman et al., 1992).

\section{Retrograde transport}

Neurotrophins were radio-iodinated to specific activities of $2800-5800$ $\mathrm{cpm} / \mathrm{fmol}$ using the lactoperoxidase method as described previously (DiStefano et al., 1992). In anesthetized animals $(127-170 \mathrm{mg} / \mathrm{kg}$ chloral hydrate, $26-36 \mathrm{mg} / \mathrm{kg}$ pentobarbital), the right sciatic nerve (at the level of the tendon of the obturator internus muscle) was injected with $1 \mu \mathrm{l}$ of $\left[{ }^{125} \mathrm{I}\right]$ neurotrophin. After $18 \mathrm{hr}$, rats were killed and the right (ipsilateral) and left (contralateral) lumbar 4th and 5th (L4, L5) DRG were removed, placed in $4 \%$ paraformaldehyde, and counted in a gamma counter. Counts per minute for right L4 and L5 DRG were pooled and compared to those of the left ganglia. In some experiments, lumbar spinal cord was also removed and counted. Emulsion autoradiography was performed as described previously (DiStefano et al., 1992).

\section{Functional studies}

Behavioral training. Groups of 20-30 animals were conditioned to perform goal-directed locomotor tasks for 7-10 d before drug treatment. All behavioral testing was done during the animals' dark cycle to optimize activity levels. After 1 week acclimation to the vivarium, animals were water-deprived with access to water only during testing sessions (15 min daily). Simple overground locomotion was tested on a $15-\mathrm{cm}$-wide, $250-\mathrm{cm}$-long runway lined with white paper. The hindpaws were painted with black tempera paint to obtain a permanent record of footprints for a foot-fall diagram analysis. Precise locomotion, which requires accurate paw placement for successful completion, was tested on two runways: (1) a 185-cm-long, 4-cm-diameter beam, demarcated into four zones by a $0.8 \mathrm{~cm}$ line painted along the length (see Fig. 4); (2) a 185-cm-long grid made from ADPI garden fencing material (Kunkel-Bagden and Bregman, 1990).

After training, but before pyridoxine or neurotrophic factor administration, three baseline measurements were collected for each of the behavioral tasks. The animals were then retested at least every fourth day throughout the course of the experiment. Two or three cohorts of 5-10 animals per group were studied in each experiment. Data from duplicate cohorts were combined. The bioactivity of NT-3 was verified at the start and finish of each experiment as described previously (DiStefano et al., 1992). Before the start of each experiment, the NT-3 and vehicle solutions were aliquoted and individual vials coded with the animals' numbers and treatment days to keep investigators blinded to treatment groups.

Quantitative analysis. Three spatial parameters of simple overground locomotion-base of support, stride length, and intrastep distance-were analyzed from footprint records. Measurements from 10 trials (step cycles) were made with the aid of an image analysis system (Java-Jandel) for each parameter. The criteria for measuring the base of support and stride length were adapted from Kunkel-Bagden and Bregman (1990), and intrastep distance was defined as the distance between the right and left hindlimbs within one step cycle along the $y$-axis (see illustration in Fig. 3). Changes in the pattern of locomotion were determined by calculating the linear regression (slope) of each measure versus time. The goodness-of-fit for individual slope calculations was determined by the $r^{2}$ value.

Precise locomotion tasks were videotaped for each testing session. A foot-fault analysis of grid walking was determined by counting the number of times a right or left hindlimb missed a rung of the grid (error). Quantitation of beam walking was carried out by scoring 10 trials (step cycles) from videotape played at slow motion. A 4-point scoring system was used based on the placement of the hindlimb paw pad on the beam in relation to the $0.8 \mathrm{~cm}$ stripe painted along the beam (see Fig. 4). A performance score for each animal was calculated from the sum of scores for 10 trials. The time to cross each of the runways was also recorded, and the speed of locomotion was calculated. A maximal time of $60 \mathrm{sec}$ was used for animals that traversed the beam slowly.

Drug administration. We tested the therapeutic efficacy of NT-3 in a protection paradigm in which $400 \mathrm{mg} / \mathrm{kg}$ pyridoxine (Sigma, St. Louis, MO) was injected intraperitoneally twice a day. The pyridoxine was formulated at $50 \mathrm{mg} / \mathrm{ml}$ in distilled water prepared immediately before injection. Recombinant human NT-3 (2, 5, or $20 \mathrm{mg} / \mathrm{kg}$ ) was administered subcutaneously once daily to half of the animals receiving pyridoxine; the other half were injected with a vehicle solution. Another group of animals received daily injections of NT-3 only, as a control. A pilot study indicated that intraperitoneal injections of vehicle had no adverse effect on the behavioral tasks being examined and, therefore, this control group was not included in subsequent experiments. Each experiment was continued until a specific proportion of the animals reached a criterion of behavioral impairment (neuropathic criterion). The neuropathic criterion was attained when $50 \%$ of the animals in a two-cohort experiment (pyridoxine \pm NT-3) exhibited beam scores of "4" (hindpaw not in contact with beam surface; see Fig. 4) 4 or more times out of 10 beam walking trials. This criterion-based approach controlled for potential intercohort differences in terms of pyridoxine potency (J. Sladky, personal communication).

A second series of experiments was conducted to evaluate whether pyridoxine administration resulted in permanent structural changes in DRG neurons and their processes. These experiments incorporated a recovery phase to determine whether NT-3 administration also enhanced the return of sensorimotor function after cessation of pyridoxine administration. Two groups were tested, both of which received $400 \mathrm{mg} / \mathrm{kg}$ pyridoxine twice a day for $8 \mathrm{~d}$ (at which point $50 \%$ of animals had reached criterion on beam walking) followed by $12 \mathrm{~d}$ of recovery. For the entire $20 \mathrm{~d}$ of the experiment, one group received $5 \mathrm{mg} / \mathrm{kg} \mathrm{NT}-3$, the other group a vehicle solution. A 12 day recovery was chosen based on pilot data revealing that pyridoxine-intoxicated animals reached a behavioral plateau $12 \mathrm{~d}$ after cessation of pyridoxine.

Electrophysiology. In one experiment, terminal electrophysiological recordings were carried out the day after the last injection of pyridoxine with or without $20 \mathrm{mg} / \mathrm{kg}$ NT-3. Animals were anesthetized as above after receiving atropine $(0.5-1.0 \mathrm{mg} / \mathrm{kg})$ to minimize respiratory secretions. Core temperature was maintained between 37 and $38^{\circ} \mathrm{C}$. The hindlimbs were secured at an angle of $30-45^{\circ}$ to the long axis of the body. For EMG recordings, a monopolar EMG recording electrode, serving as the active electrode (Jari Electrode Supply), was inserted between the 4th and 5th digits, parallel to the long axis of the foot. The reference electrode was inserted into the 5th digit of the same foot, and a ground electrode was inserted into the tail. Recordings were made bilaterally to minimize variability (Pérot and Almeida-Silveira, 1994). The tibial nerve was stimulated through a monopolar cathodal stimulating electrode (Jari). An equivalent anode electrode was inserted into the calf muscles $1 \mathrm{~cm}$ proximal to the cathode. On the right side, the sciatic nerve was also stimulated through a cathodal needle electrode in the proximal thigh, with the anode inserted $1 \mathrm{~cm}$ rostral.

The position of the active recording electrode was adjusted to maximize the $\mathrm{M}$ wave amplitude. Constant-current stimuli were delivered through a stimulus isolator (AMPI). For each stimulation, the position of stimulating electrodes was adjusted to bring thresholds to evoke $\mathrm{H}$ or $\mathrm{M}$ waves below $1.0 \mathrm{~mA}$. Recordings were made with a stimulus that evoked a maximum-amplitude $\mathrm{H}$-reflex $\left(H_{\max }\right)$ and again at $1.25 \times$ the minimum stimulus intensity sufficient to evoke a maximum-amplitude $M$ wave $\left(M_{\max }\right)$. Data from 8 stimuli at each of these intensities were averaged for quantitative analysis. Peak-to-peak amplitudes of $\mathrm{H}$ and $\mathrm{M}$ waves were measured. To normalize the amplitudes of the $\mathrm{H}$ reflexes, their amplitudes were divided by those of the $\mathrm{M}$ waves to obtain the $H_{\max } / M_{\max }$ ratio. Stability of latencies to tibial and sciatic stimulation was verified to ensure meaningful calculation of conduction velocities. When late waves were inconsistently present, latency measurements for calculation of sensory conduction velocity were made from single traces in which long-latency waves appeared. If $\mathrm{H}$ reflexes could not be consistently elicited, stimulation was raised gradually to at least $10 \times$ threshold for the $\mathrm{M}$ wave to verify the absence of the $\mathrm{H}$ reflexes for a wide range of stimulus intensities.

Sensory and motor conduction velocity were calculated as the distance between sciatic and tibial cathodes divided by the difference in latencies of responses to stimulation at the two locations. Latencies were measured to the first major peak for the $\mathrm{M}$ or $\mathrm{H}$ waves. Two separate measurements of $\mathrm{M}$ and $\mathrm{H}$ wave amplitudes in response to tibial stimulation were made on one side, and one was made on the other. An unbiased average 

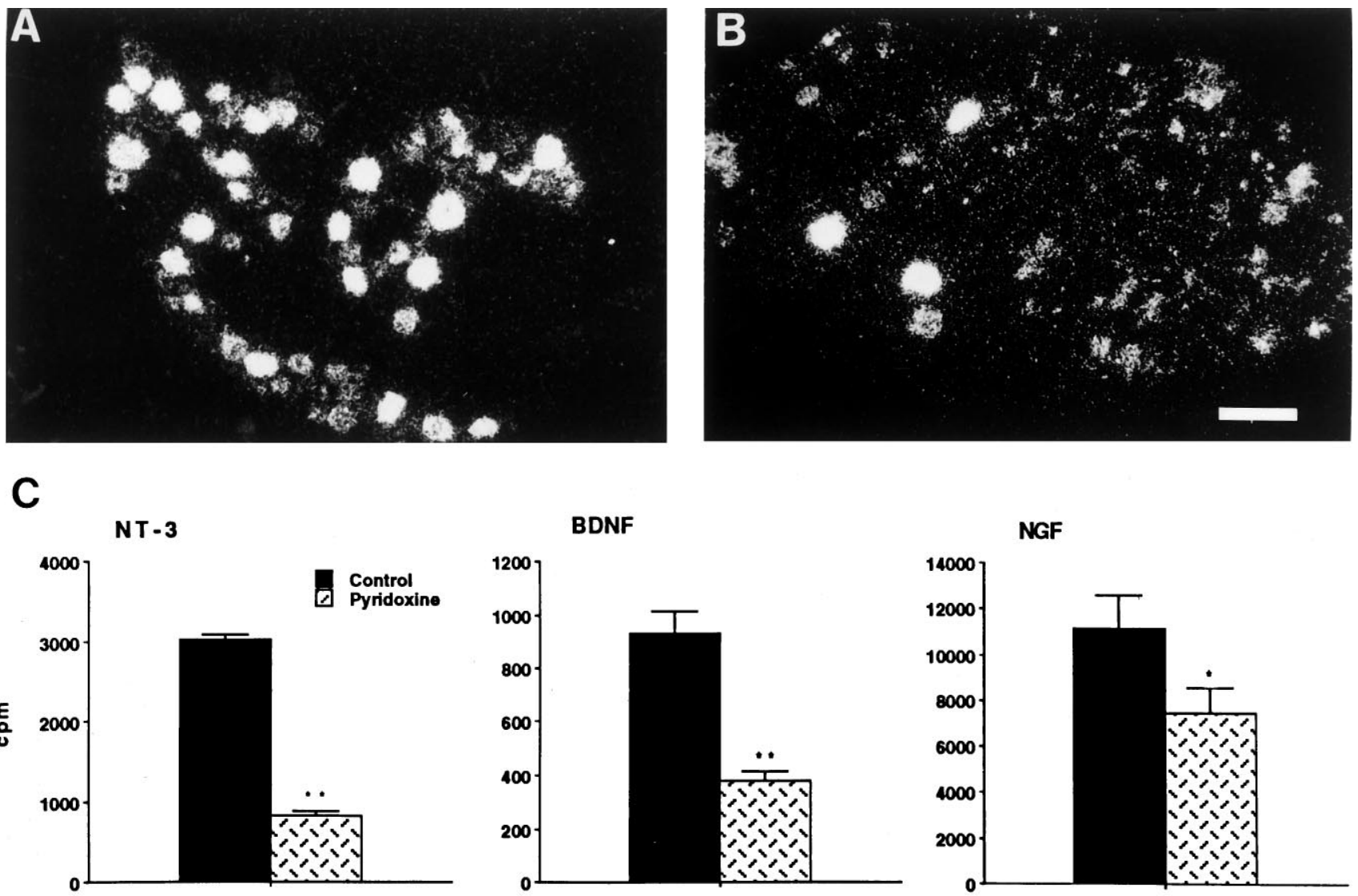

Figure 1. Distribution of TrkC mRNA and retrograde axonal transport of ${ }^{125}$ I-labeled neurotrophins in the adult rat DRG. TrkC in situ hybridization $(A)$ and accumulation of radiolabeled NT-3 $(B)$ in DRG neurons. Note the predominance of silver grains over large neurons $(40-50 \mu \mathrm{m}$ in diameter). Scale bar, $100 \mu \mathrm{m}$. Accumulation of radiolabeled NT-3, BDNF, and NGF in L4/5 DRG after injection into the right sciatic nerve is depicted quantitatively in $C$. The solid bars represent age- and weight-matched controls, and the speckled bars represent animals that received $12 \mathrm{~d}$ of pyridoxine treatment. Values are mean \pm SEM for $4-6$ animals per group; ${ }^{*} p<0.05,{ }^{* *} p<0.01$ (ANOVA).

response amplitude to tibial stimulation $\left(M_{\max }\right.$ and $\left.H_{\max } / M_{\max }\right)$ on the two sides was calculated. ANOVAs were done on electrophysiological data, with post hoc testing using Fisher's Protected Least Significant Difference test (Statview, Abacus Concepts, Calabasas, CA). For ANOVA, data for $H_{\max } / M_{\max }$ ratios were transformed using the square root transformation to equalize variances (untransformed data are presented in Fig. 6). Correlation of the $H_{\max } / M_{\max }$ ratio to beam behavior was tested using the nonparametric Spearman Rank Correlation to avoid assumptions about linearity of the relationship.

\section{Histopathology}

Anesthetized animals were perfused through the heart with warm heparinized saline followed by ice-cold $4 \%$ paraformaldehyde. The spinal cord and lumbar DRG were dissected and stored in fresh fixative. The lumbar enlargement of the spinal cord was transferred from fixative to $30 \%$ sucrose for $3 \mathrm{~d}$ before sectioning at $30 \mu \mathrm{m}$ on a sliding microtome. Two blocks (coded for treatment groups) were cut together, and free-floating sections were processed for degenerating nerve cell processes with a cupric-silver method (Desclin and Escubi, 1975).

The L4 and L5 ganglia from the same animals $(n=6$ per treatment group) were embedded in paraffin, and sections were cut at $6 \mu \mathrm{m}$ and processed for Nissl substance with cresyl violet. Neuronal counts were made on every 10th section throughout the ganglia, and area measurements were made with the aid of an automated image analysis system (Java-Jandel). Only cells with a distinct nucleolus were included in the analysis.

\section{RESULTS}

Daily administration of pyridoxine produced profound proprioceptive dysfunction as determined by functional sensory-motor testing. Concomitant treatment with NT-3 attenuated the pyridoxine-induced impairment and prevented the associated primary afferent degeneration. The following data illustrate the nature of neurotoxicity of pyridoxine toward large sensory fibers and demonstrate the protective effects of NT-3.

\section{Large sensory neurons are NT-3-responsive}

In situ hybridization studies revealed that TrkC mRNA was expressed in most of the large neurons of the adult rat DRG, as well as in a fraction of small neurons (Fig. $1 A$ ). To assess the presence of functional TrkC receptor protein, uptake of radiolabeled NT-3 into spinal sensory neurons was assessed. After $\left[{ }^{125} \mathrm{I}\right] \mathrm{NT}-3$ injection into the sciatic nerve, the pattern of neuronal labeling in L4/L5 DRG produced by retrograde axonal transport of [ $\left.{ }^{125} \mathrm{I}\right] \mathrm{NT}$ 3 was similar to the distribution of TrkC mRNA. The largest neurons in the ganglia were moderately to very heavily labeled, and moderate labeling was also observed in some small neurons (Fig. 1B).

\section{Reduction of NT-3 transport in pyridoxine-intoxicated rats}

Over an $8 \mathrm{~d}$ treatment period, pyridoxine intoxication $(800 \mathrm{mg}$. $\mathrm{kg}^{-1} \cdot \mathrm{d}^{-1}$ ) produced a $70 \%$ decrease in the retrograde axonal transport of NT-3. In comparison, BDNF and NGF transport were reduced by $\sim 60$ and $40 \%$, respectively (Fig. $1 C$ ). The smaller but parallel reductions in BDNF and NGF transport may reflect the partial overlap in the distribution of TrkC with TrkB (McMahon et al., 1994), and possibly TrkA in DRG, and also correspond 


\section{PROTECTION PARADIGM}

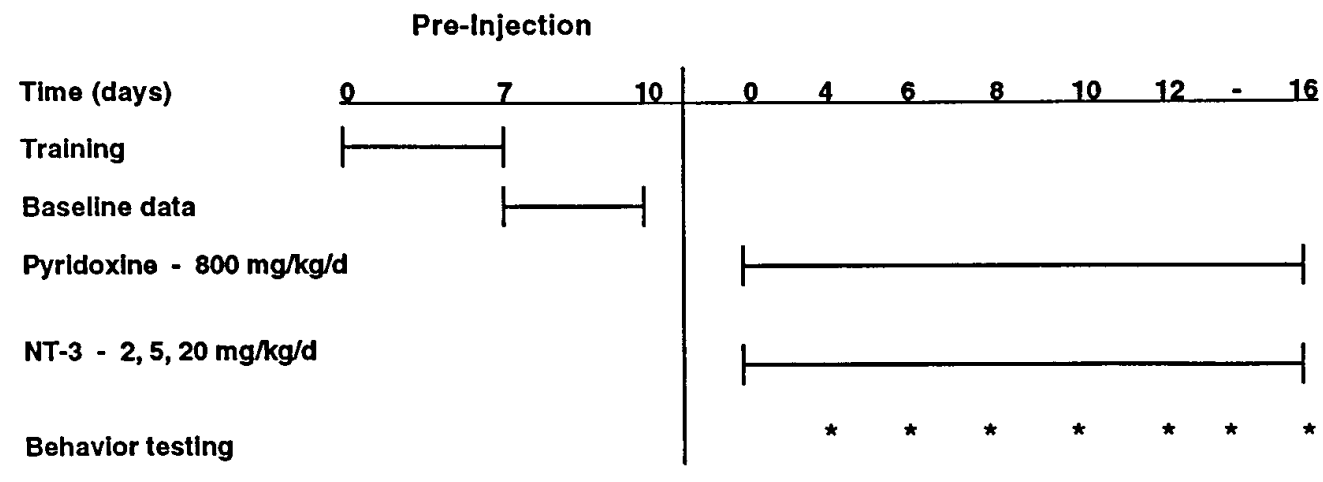

\section{Analyses}

Behavior - Simple and precise locomotion

Physlology - EMG response to peripheral nerve stimulation : $M$ and $H$ waves

Figure 2. Experimental protocol used for evaluation of the behavioral and electrophysiological deficits produced by pyridoxine and their attenuation by NT-3.

to the overlap in the retrograde labeling patterns of these factors (DiStefano et al., 1992). Thus, it is also possible that pyridoxine may impair NGF- or BDNF-responsive DRG neurons. Formal functional testing to evaluate the potential impairment of sensory modalities mediated by NGF- or BDNF-responsive neurons was not carried out in this study; however, none of the animals displayed any tactile hyper- or hyporesponsiveness during handling for injections or behavioral testing.

\section{Effect of NT-3 on pyridoxine-induced neuropathy}

The experimental paradigm used for the NT-3 neuroprotection studies is depicted in Figure 2. Rats received pyridoxine $(800 \mathrm{mg}$ $\left.\cdot \mathrm{kg}^{-1} \cdot \mathrm{d}^{-1}\right)$, NT-3 $\left(2,5\right.$, or $\left.20 \mathrm{mg} \cdot \mathrm{kg}^{-1} \cdot \mathrm{d}^{-1}\right)$, or a combination of both agents for 8-16 d. Apart from the impairment of sensorymotor function apparent in pyridoxine-treated animals, there were no signs of adverse, nonspecific effects of treatment, with the exception of transient (10-30 min) writhing/stretching after intraperitoneal injection of pyridoxine. Grooming, social interactions, and activity levels were all within a normal range, and there were no signs of general morbidity or significant fluctuation in body weight.

Sensory-motor impairments, manifest as a broadening of the base of support during simple overground locomotion, and faulty paw placement during precise locomotion tasks were observed by the fourth day of chronic pyridoxine intoxication. These symptoms progressed to a loss of proprioception in animals treated with pyridoxine alone, as indicated by the inability of the animals to complete successfully any precise locomotion task and by grossly abnormal foot-fall patterns by $12-16 \mathrm{~d}$ of intoxication. During simple overground locomotion, the ability of the hindlimbs to support the animal was severely compromised. Affected animals exhibited a lowered center of gravity to the extent that the abdomen was in constant contact with the platform surface. Hindlimb extension during terminal stance phase was exaggerated and prolonged, and attempts at flexion for the swing phase resulted in dragging the dorsum of the paw along the platform surface. Qualitatively, the impairments seen on precise locomotion tasks were also profound. As with simple locomotion, the center of gravity was lowered, with the abdomen in contact with the beam or grid runways. Normal contact of the hindlimb with the runways was not maintained in either of the precise locomotion tasks; in the beam task, the hindpaw slipped from the top surface of the beam, the animals straddled the beam or lost balance and fell off, and in the grid-walking task hindlimbs dangled through the grid openings. As detailed below, NT-3 substantially attenuated these pyridoxine-induced impairments in locomotion.

\section{Simple overground locomotion}

Changes in the locomotion pattern were expressed as the linear regression (slope) of measurements for three spatial parameters of the step cycle in relationship to time. As shown in Figure 3, rats given pyridoxine for $8 \mathrm{~d}$ showed a broadening of the base of support and a reduction in stride length and intrastep distance. The degree of variance for the distances measured in the slope calculations was high for the base of support $\left(r^{2}=0.4 \pm 0.3\right)$ and low for stride length and intrastep distance $\left(r^{2}=0.7 \pm 0.3\right.$ and $0.7 \pm 0.2$, respectively), indicating that the latter two parameters exhibit a progressive decline with pyridoxine treatment. The variability in the base of support reflects qualitative observations that the initial change in the gait pattern is an increase in the base of support that subsequently plateaus or declines as the neuropathy develops. Administration of NT-3 $\left(5 \mathrm{mg} \cdot \mathrm{kg}^{-1} \cdot \mathrm{d}^{-1}\right)$ during the course of pyridoxine treatment prevented the widening of the base of support and reversed the decline in stride length and intrastep distance, such that stride length increased over the $8 \mathrm{~d}$ period with a concomitant increase in intrastep distance. In a pilot study investigating the effect of prolonged training on the rat step cycle, we also observed an increase in step-cycle distance similar to that seen with the group of pyridoxine-intoxicated rats treated with NT-3. As predicted, the goodness-of-fit for points on the calculated slopes in the NT-3-treated animals was lower than in the vehicle-treated animals $\left(r^{2}=0.4 \pm 0.3,0.4 \pm 0.4\right.$, and $0.4 \pm 0.3$ for base of support, stride length, and intrastep distance, respectively). Thus, pyridoxine intoxication produced a reversal of the normal increase in stride length and intrastep distance observed as a function of conditioning; NT-3 cotreatment with pyridoxine prevented this reversal. Quantitative comparisons of these parameters were not made beyond $8 \mathrm{~d}$, because the foot-fall patterns of animals treated with pyridoxine alone became grossly abnormal and uninterpretable at later time points. Qualitatively, the changes in the step cycle of pyridoxine-intoxicated rats were indicative of a proprioceptive deficit. The terminal extension phase of stance was prolonged and hyperextended, suggesting that the signal for initiating the swing phase, which is dependent on 


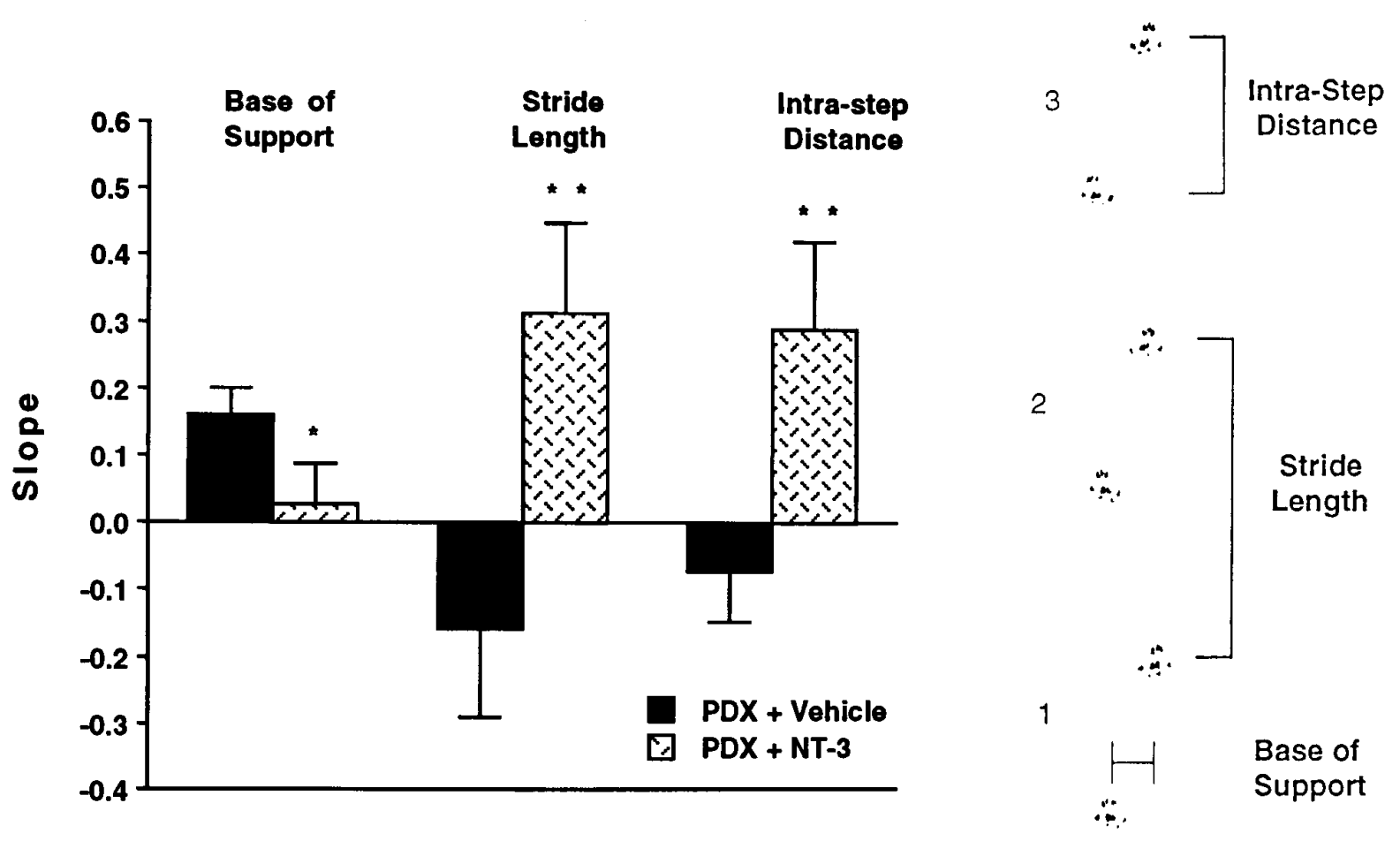

Figure 3. Quantitative analysis of simple overground locomotion in pyridoxine-intoxicated rats treated with vehicle or NT-3. Measurements of the base of support, stride length, and intrastep distance were taken from foot-fall diagrams. On the right are actual footprints from a normal adult rat, illustrating the parameters examined over three step cycles. Quantitatively, changes in the pattern of locomotion after $8 \mathrm{~d}$ of pyridoxine administration alone or with NT-3 $\left(5.0 \mathrm{mg} \cdot \mathrm{kg}^{-1} \cdot \mathrm{d}^{-1}\right)$ were determined by slope calculations $(\mathrm{cm} / \mathrm{d})$. NT-3 prevented the broadening of the base of support and reductions in stride length and intrastep distance observed with pyridoxine intoxication. Conditioned, control animals or those receiving NT-3 alone showed comparable enhancement of stride length and intrastep distance over a similar time course (see text). Values are mean \pm SEM for 14-15 animals/group obtained from two experiments; ${ }^{*} p<0.05 ;{ }^{*} p<0.01$ (Student's $t$ test).

joint angle position (Jankowska, 1989), was distorted or lacking. In rats cotreated with NT-3, the terminal extension phase of the step cycle was unaltered.

\section{Precise locomotion}

To test proprioceptive function specifically, rats were pretrained on grid and beam runways, tasks requiring accurate paw placement. Testing on the grid runway used the number of foot falls through the grid openings (errors) as an indication of dysfunction in paw placement. After pyridoxine administration for $12 \mathrm{~d}$, the animals receiving vehicle were essentially unable to cross the grid runway (the hindlimbs remained suspended through the grid openings), whereas animals treated with NT-3 were able to complete the task throughout the course of the experiment (data not shown). The toxic effects of pyridoxine and the attenuating effects of 5 or $20 \mathrm{mg} / \mathrm{kg} \mathrm{NT-3}$, as observed in the beam task, are illustrated in Figure 4. The impairment in animals receiving pyridoxine alone was revealed by the extent that the hindpaws were unable consistently to maintain contact with the top of the beam surface for 10 step cycles (range of performance scores was 2-4; see legend to Fig. 3 for details). Consequently, many of these animals crossed the beam with great difficulty or were unable to traverse the beam at all (Fig. $4 B$ ). In contrast, animals cotreated with NT-3 readily crossed the beam with paw pads mostly contacting the beam surface above the "score" line (Fig. 4C). Quantitatively, groups receiving 5 or $20 \mathrm{mg} / \mathrm{kg}$ NT-3 performed significantly better on the beam than the vehicle control group (Fig. $5 A, C)$. The speed of precise locomotion decreased markedly in intoxicated animals (Fig. $5 B, D$ ). This was attenuated by NT-3 at doses of 5 or $20 \mathrm{mg} / \mathrm{kg}$.
In a second series of experiments, pyridoxine treatment was stopped when a predetermined number of animals reached neuropathic criterion (achieved after $8 \mathrm{~d}$ of intoxication), but NT-3 or vehicle treatment was continued for an additional $12 \mathrm{~d}$. This extended time course was used to allow evaluation of the more slowly evolving, permanent structural changes to DRG neurons resulting from pyridoxine treatment and to assess the potential neuroprotective effects of NT-3 on such changes. In one experiment, animals treated with pyridoxine exhibited significant neuropathy by $8 \mathrm{~d}$, and this was attenuated by cotreatment with $5.0 \mathrm{mg} / \mathrm{kg}$ NT-3. During the subsequent off-pyridoxine phase, both groups of animals showed some recovery of function. For the simple overground locomotion task, the intrastep distances and stride lengths were not different between the two groups. Means \pm SEM (in cm) for intrastep distance were $9.40 \pm 0.46$ and $8.15 \pm 0.33$, for stride length were $18.84 \pm 0.45$ and $18.08 \pm 0.50$, for PDX + vehicle and PDX +5 $\mathrm{mg} / \mathrm{kg}$ NT-3, respectively. However, the base of support remained significantly greater in the vehicle group compared to the NT-3treated group $(4.74 \pm 0.31$ vs $3.81 \pm 0.15, p>0.05)$. On the beam task, animals treated throughout with NT-3 performed significantly better. The mean performance score on the last testing day (day 12 of recovery) for the vehicle-treated group was $1.82+0.25$ compared to the NT-3-treated group, which was $1.21+0.12$ (repeatedmeasures ANOVA; treatment, $p=0.04$; time $p=0.0001$; interaction $p=0.05)$.

\section{Electrophysiology}

The results of EMG recording during peripheral nerve stimulation in pyridoxine-intoxicated animals treated for $16 \mathrm{~d}$ were consistent with selective toxicity to sensory, but not motor nerve function. 
A.

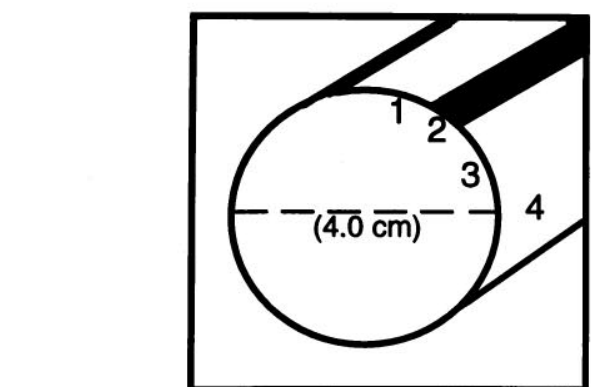

1

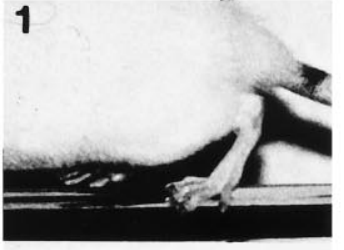

2

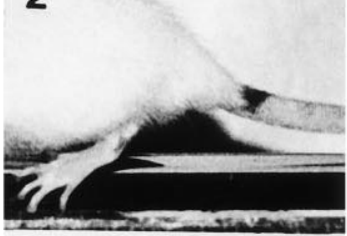

3

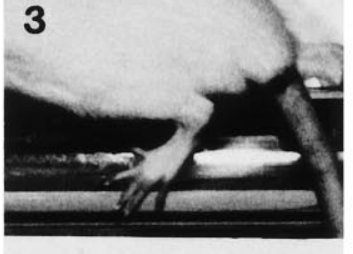

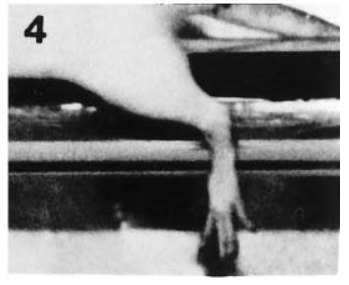

1 - Paw pad contacts beam medial to score line

2 - Paw pad contacts score line

3 - Paw pad contacts beam lateral to or below score line

4 - Paw pad does not contact beam, limb is suspended

\section{B. Pyridoxine + Vehicle}
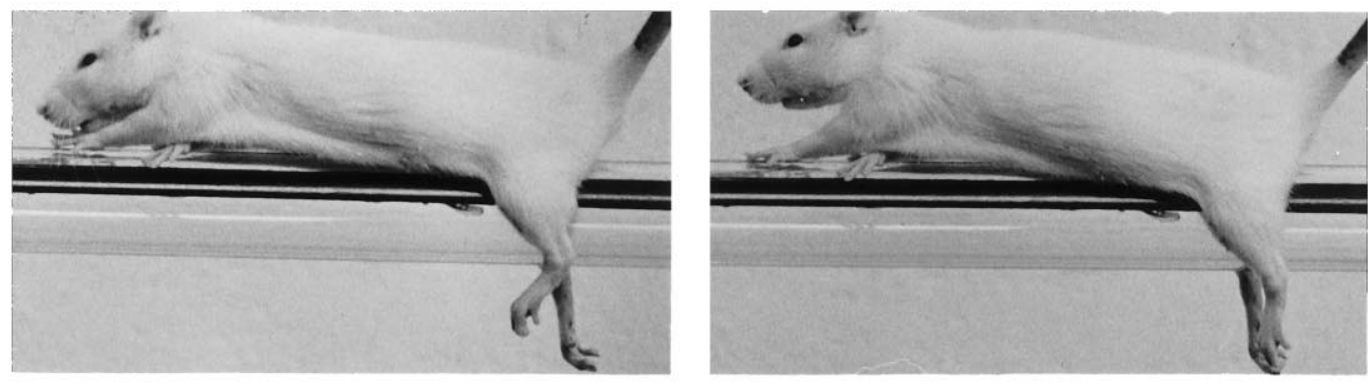

\section{Pyridoxine $+\mathrm{NT}-3$}
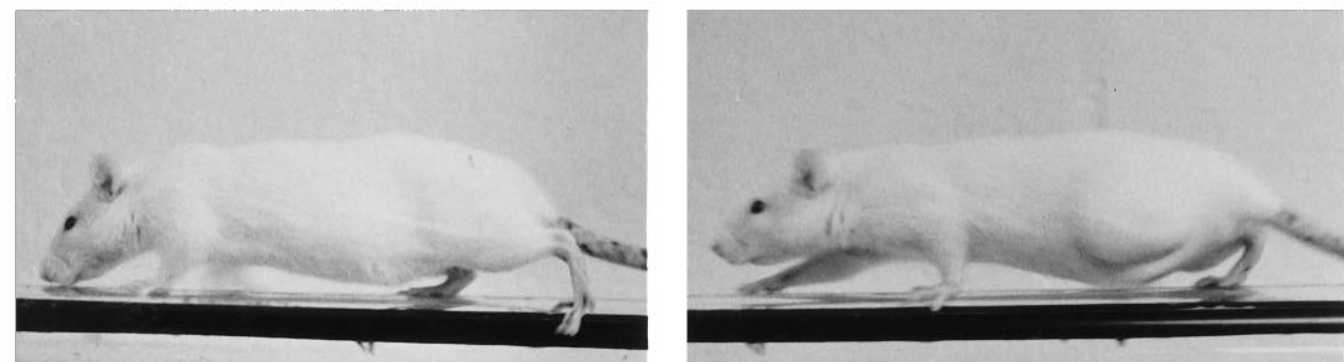

Figure 4. Illustration of the beam-walking precise locomotion task. The scoring system for beam walking is depicted in $A$. Paw placement zones were demarcated on a plastic beam $4.0 \mathrm{~cm}$ in diameter by a $0.8 \mathrm{~cm}$ line painted along the length of the beam runway $1.4 \mathrm{~cm}$ lateral to midline. The placement of the paw pad (metatarsophalangeal joint) in relation to the score line was recorded from slow-motion videotape as shown in $A$. The photographs illustrate an example of each score; note that contact of the paw pad (not the digits) was used in the analysis. $B, C$, Photographs of pyridoxine-treated (12 d) rats crossing the beam runway. The animal in $B$ was cotreated with vehicle and was unable to walk across the beam successfully; the hindpaw was not in contact with the beam (score $=4)$. The animal in $C$ was treated with NT-3 $\left(20 \mathrm{mg} \cdot \mathrm{kg}^{-1} \cdot \mathrm{d}^{-1}\right)$. The series of photographs depicts one step cycle of the rat independently crossing the beam with the hindlimbs contacting the top surface of the beam (score $=1)$.

\section{Sensory nerve function}

The $\mathrm{H}$ reflex was severely attenuated in rats receiving pyridoxine. An example of an EMG potential recorded from one animal in each of the three groups is presented in Figure $6 \mathrm{~A}$. Of the 10 animals in the pyridoxine alone group, 5 had no consistently detectable late waves and the remaining animals showed substantial reductions in $\mathrm{H}$ wave amplitude. In contrast, the $\mathrm{H}$ wave was consistently detectable in all but 1 of the 10 animals receiving pyridoxine and NT-3. Quantitative results are presented in Figure $6 B$. Sensory conduction velocity was lower in the pyridoxine group than in the NT-3 control group $(p<0.01)$. Among the animals for which this measurement was made (conduction velocity could not be calculated for animals with no observable $\mathrm{H}$ wave), no significant differences were found among other pairs of groups. Values 
A

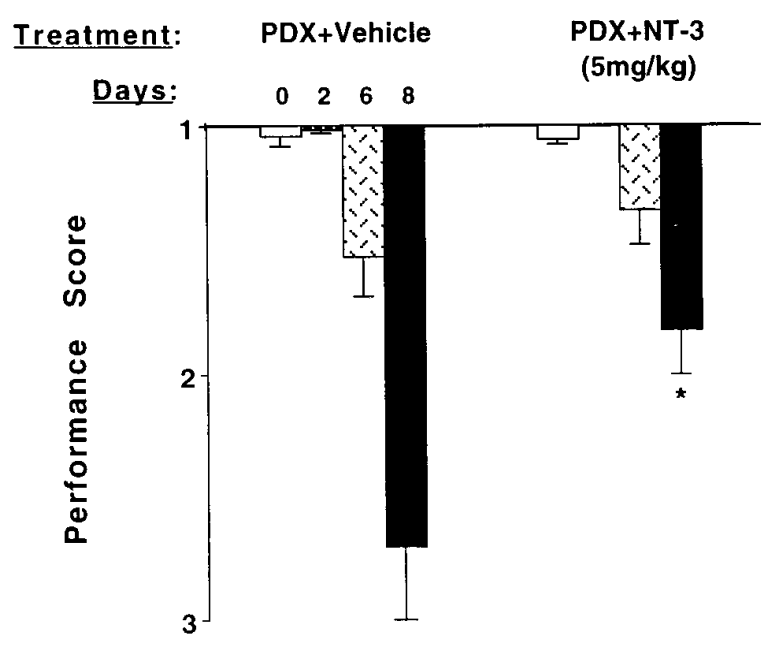

B

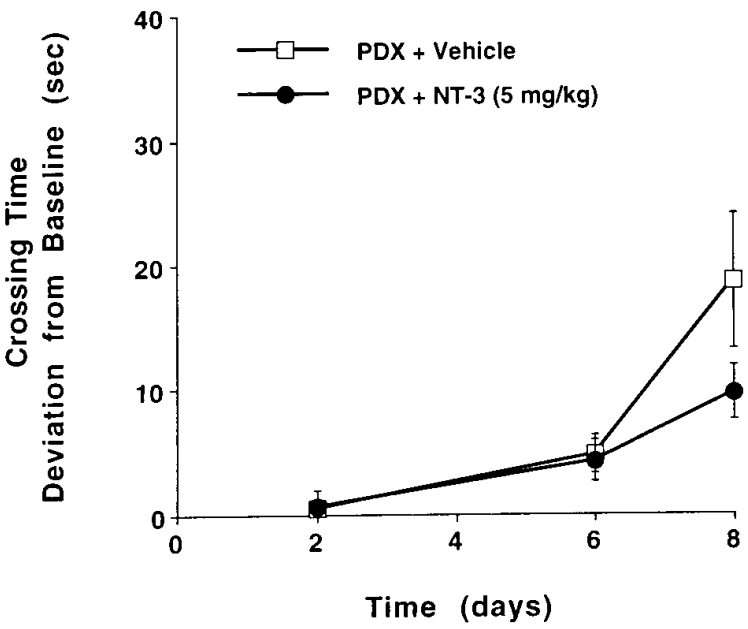

C

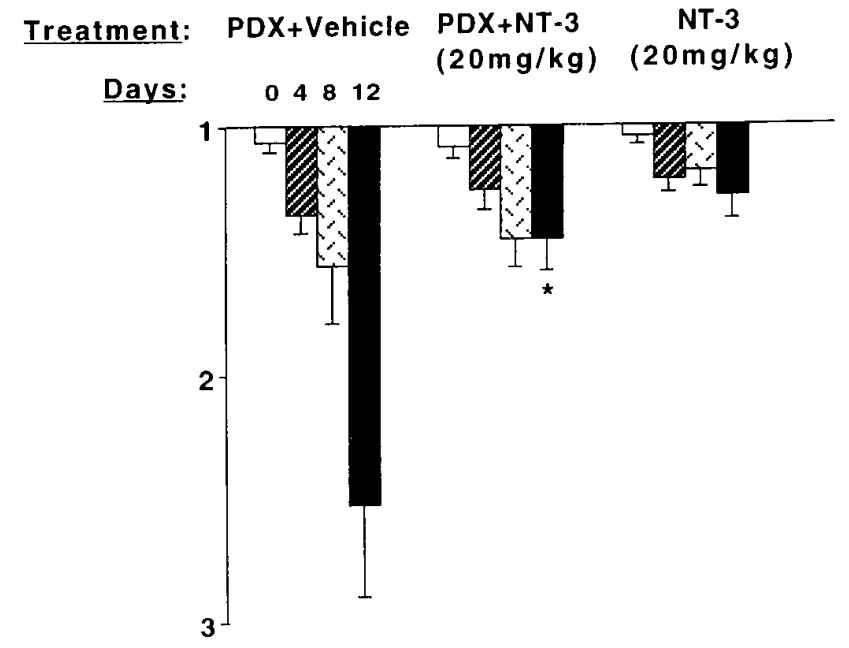

D

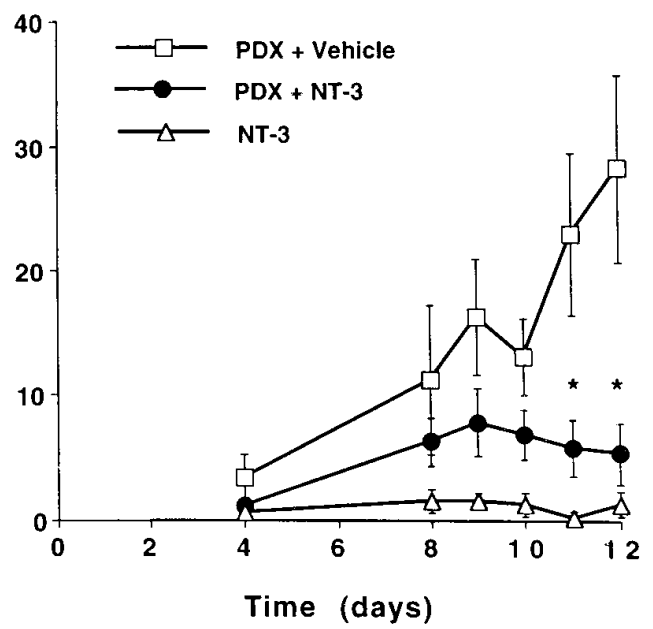

Figure 5. Quantitative analysis of performance score and beam-crossing time in the precise locomotion task. $A$, Performance score of beam walking in pyridoxine-intoxicated animals treated with either vehicle or NT-3 $\left(5 \mathrm{mg} \cdot \mathrm{kg}^{-1} \cdot \mathrm{d}^{-1}\right)$. Each bar represents a separate testing day. The open bar delineates baseline values (day 0 ), and the subsequent bars score at 2, 6, and $8 \mathrm{~d}$. Values are mean \pm SEM for 10 animals/group. Repeated-measures ANOVA: Treatment $p=0.06, F=3.7$; Time $p=0.0001, F=30.4$; Interaction $p=0.01, F=3.9$. Post hoc Fischer test, ${ }^{*} p<0.02$ PDX + Vehicle compared to PDX + NT-3. $B$, Crossing times in the beam runway task for the same groups shown in $A$; results expressed as deviation from day 0 baseline. Repeated-measures ANOVA: Treatment $p=0.19, F=1.8$; Time $p=0.0001, F=15.4$; Interaction $p=0.14, F=2.0$. $C$, Performance score of beam walking in an NT-3 $\left(20 \mathrm{mg} \cdot \mathrm{kg}^{-1} \cdot \mathrm{d}^{-1}\right)$ control group and pyridoxine-intoxicated animals treated with either vehicle or NT-3 $\left(20 \mathrm{mg} \cdot \mathrm{kg}^{-1} \cdot \mathrm{d}^{-1}\right)$. The open bar delineates baseline values (day 0), and the subsequent scores are 4, 8, and $12 \mathrm{~d}$. Values are mean \pm SEM for 10 animals/group. Repeated-measures ANOVA: Treatment $p=0.0001, F=12.956$; Time $p=0.0001, F=9.133$; Interaction $p=0.0001, F=4.1$. Post hoc Fischer test, ${ }^{*} p<0.001$ PDX + Vehicle compared to PDX + NT-3 or NT-3. $D$, Crossing times in the beam runway task for the same groups shown in $C$; NT-3 partially prevents the increased crossing time observed with pyridoxine toxicity. Repeated-measures ANOVA: Treatment $p=0.001, F=13.409$; Time $p=0.0011$, $F=4.354$; Interaction $p=0.0015, F=3.099$. Post hoc Fischer test, $p<0.001$ PDX + Vehicle compared to PDX + NT-3 or NT-3.

for sensory conduction velocity [mean $\pm \mathrm{SD}$ (in $\mathrm{m} / \mathrm{sec}$ )] were as follows: NT-3 control, $37.2 \pm 4.9(n=6)$; pyridoxine and vehicle, $23.7 \pm 9.7(n=6)$; pyridoxine and NT-3, $31.4 \pm 8.6(n=10)$; uninjected control, $33.8 \pm 1.8(n=3)$. The $\mathrm{H}$ wave amplitudes correlated with the beam scores of the animals on the precise locomotion task. Figure $6 C$ illustrates a curvilinear relationship of the $\mathrm{H}$ wave with beam score in which there appears to be an inflection point on the curve. This suggests a critical point in the neuropathic process. For low or "normal" beam scores, there is a range of $\mathrm{H}$ wave amplitudes, which likely reflects biological variability. However, at some critical value for the $\mathrm{H}$ wave amplitude (suggesting pathology) there is a spread of beam scores (indicating dysfunction).

\section{Motor nerve function}

Neither the amplitude of the motor EMG response (M wave) nor the motor conduction velocity varied among treatment groups. Amplitudes (in $\mathrm{mV}$ ) were: untreated control, $28.5 \pm$ 8.7; NT-3 control, $25.0 \pm 5.5(n=8)$; pyridoxine and vehicle, $25.9 \pm 10.2(n=10)$; pyridoxine and NT-3, $29.5 \pm 12.0(n=$ 10). Conduction velocities (in $\mathrm{m} / \mathrm{sec}$ ) were: untreated control, $33.2 \pm 1.1(n=3)$; NT-3 control, $34.3 \pm 4.1(n=7)$; pyridoxine 
A
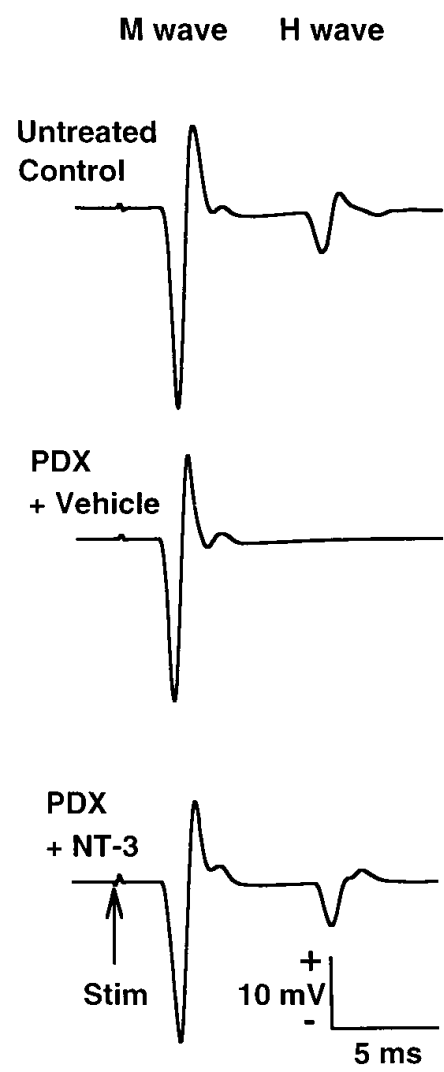
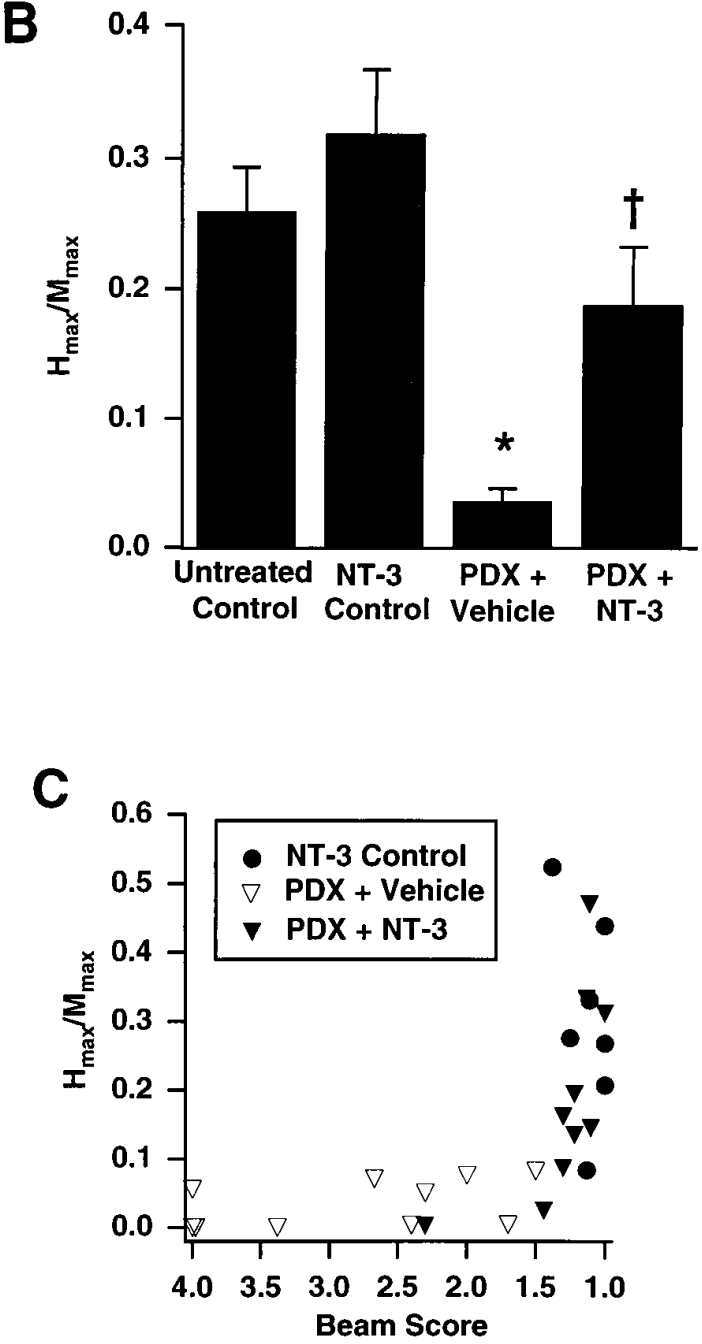

Figure 6. Electrophysiological measures of sensory-motor function in pyridoxine-intoxicated rats. EMG potentials recorded after tibial nerve stimulation illustrating the $\mathrm{M}$ wave and $\mathrm{H}$ reflex are shown for a representative animal in each of three groups $(A)$ Note the obliteration of the $\mathrm{H}$ wave with pyridoxine administration and the preservation with cotreatment with NT-3 $\left(20 \mathrm{mg} \cdot \mathrm{kg}^{-1} \cdot \mathrm{d}^{-1}\right)$. No change in $M$ wave amplitudes was observed among the groups. The changes in $\mathrm{H}$ wave amplitudes are shown quantitatively as the ratio of the maximal $\mathrm{H}$ wave amplitude to the maximal $\mathrm{M}$ wave amplitude $(B)$. Values are mean \pm SEM for 8-10 animals/group, except NT-3 alone $(n=3)$; ${ }^{*} p \leq 0.001$ for difference from each control group compared to all other groups; ${ }^{\dagger} p<0.05$ vs NT-3 control group alone (ANOVA, post hoc Fischer test). The reduction in $\mathrm{H}$ reflex correlates with the impairment of the beam-walking performance $(C)$; Spearman Rank Correlation $=0.82$ corrected for ties; $p<0.0001$. and vehicle, $29.7 \pm 3.6(n=8)$; pyridoxine and NT-3, $31.7 \pm 3.6$ $(n=10)$.

\section{Histopathological analysis}

After $8 \mathrm{~d}$ of pyridoxine treatment and $12 \mathrm{~d}$ of recovery, the integrity of the central projections of primary proprioceptive afferents was assessed using a silver stain for degenerating fibers. Figure 7 illustrates a typical spinal cord section through a lumbar segment from a pyridoxine-treated animal (Fig. 7A,B) and an animal cotreated with pyridoxine and NT-3 (5 mg/kg; Fig. 7C,D). Many large-caliber argyrophilic axonal profiles were present in the dorsal columns of the pyridoxine-intoxicated animals but were rare in animals cotreated with NT-3. These profiles are presumably the ascending collaterals of Ia afferents that degenerate as a consequence of pyridoxine administration but remain preserved with NT-3 cotreatment. Alternatively, the degeneration seen could be a combination of muscle and nonmuscle afferents that travel in the dorsal columns.

Formal stereological methods for quantitative analysis of the DRG histopathology were not done in these experiments, but raw cell counts of the L4/5 DRG indicated that there was a slight loss of neurons in the pyridoxine- and vehicle-treated rats compared to those cotreated with NT-3 (2234 \pm 110 and $2539 \pm 112$, respectively). As shown in Figure 8, the frequency of neurons with a cross-sectional area of $\geq 1000 \mu \mathrm{m}^{2}$ was greater in animals cotreated with NT-3 compared to pyridoxine alone.

\section{DISCUSSION}

Recent evidence showing distinct specificities of the neurotrophins for sensory neurons of different modalities (for review, see Lindsay, 1994) prompted our investigation of the efficacy of neurotrophins in an animal model of peripheral neuropathy. The present results show that pyridoxine produces a large sensoryfiber peripheral neuropathy in rats and that the proprioceptive deficits and associated neuropathology are attenuated by systemic administration of NT-3. The choice of NT-3 as the neurotrophic factor to test in this model was suggested by its selective effects on large neural crest-derived sensory neurons in vivo and in ovo (Hory-Lee et al., 1993; Gaese et al., 1994), preferential retrograde axonal transport of radiolabeled NT-3 to the largest neurons in the DRG (DiStefano et al., 1992), and the localization of its cognate receptor, trkC, to the same population of neurons (McMahon et al., 1994). The marked loss of large DRG neurons and the complete lack of muscle spindles in mice bearing null mutations in NT-3 or TrkC have substantiated the hypothesis that NT-3 is a critical target-derived neurotrophic factor for proprioceptive neurons (Ernfors et al., 1994; Klein et al., 1994), although 

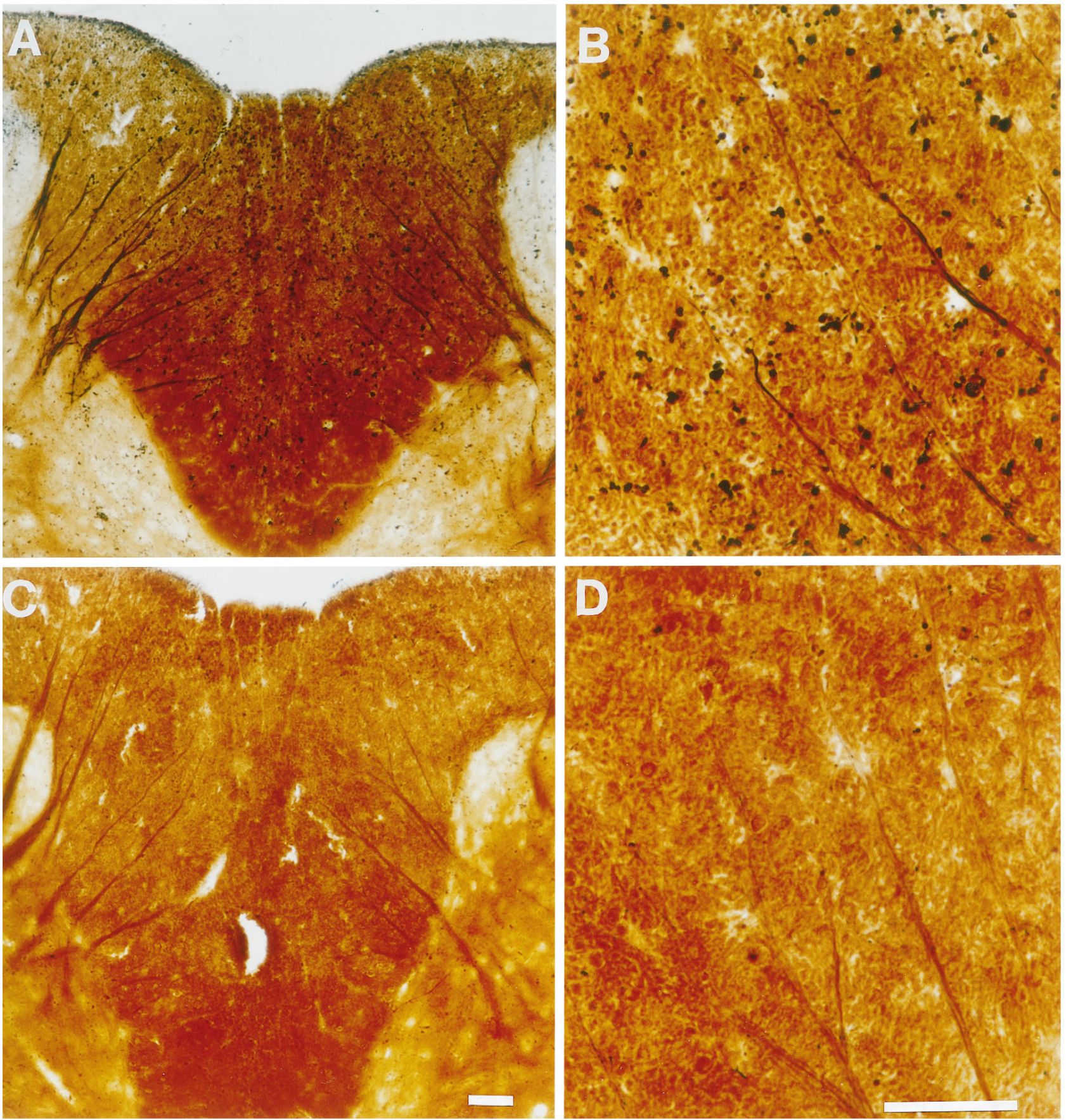

Figure 7. Pyridoxine-induced degeneration of primary afferent fibers in the dorsal columns; prevention with NT-3 treatment. Low- and high-power photomicrographs of the dorsal columns from an animal receiving pyridoxine + vehicle $(A, B$; scale bar, $50 \mu \mathrm{m})$ or pyridoxine + NT-3 $\left(5.0 \mathrm{mg} \cdot \mathrm{kg}^{-1}\right.$ $\cdot \mathrm{d}^{-1} ; C, D$; scale bar, $\left.50 \mu \mathrm{m}\right)$. Note the abundance of argyrophilic profiles in the vehicle-treated animal and the lack of degenerating profiles in the NT-3-treated animal.

it also functions as a factor for other somatic afferent and sympathetic neurons (Zhou and Rush, 1995; Airaksinen et al., 1996).

In humans, peripheral neuropathies comprise a heterogeneous group of disorders in terms of etiology, clinical manifestation, and prognosis. The diversity of the clinical symptoms is dependent on the types of peripheral nerve fibers involved in the pathology. For example, diabetic neuropathy, peripheral nerve injury, or toxic neuropathies secondary to the chemotherapeutic agents taxol (Lipton et al., 1989) or vinca alkaloids (Legha, 1986) are heterogeneous in nature. These pathologies show multimodal deficits attributable to involvement of multiple classes of sensory and/or motor fibers. In contrast, toxic neuropathies induced by pyridoxine (Albin et al., 1987) and cisplatin (Krarup-Hansen et al., 1993) are more homogeneous, producing selective proprioceptive deficits. Regardless of the type of insult, to date there is no effective treatment for peripheral neuropathies.

The rationale for selecting pyridoxine to produce an animal model of large-fiber neuropathy was based on several factors, including the selective and severe neurotoxic actions of this compound on large DRG neurons of rodents (Xu et al., 1989), dogs 


\section{L4/5 Cell Size Frequency}

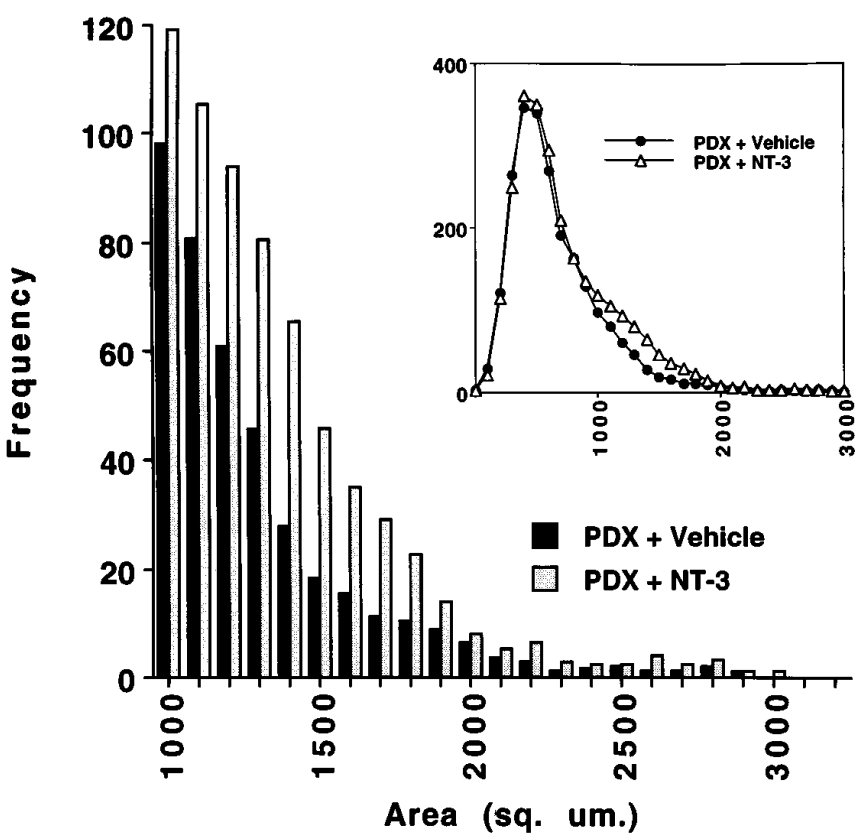

Figure 8. Size frequency histogram of L4/5 DRG neurons in pyridoxineintoxicated rats treated with either vehicle or NT-3 $\left(5.0 \mathrm{mg} \cdot \mathrm{kg}^{-1} \cdot \mathrm{d}^{-1}\right)$. After $8 \mathrm{~d}$ of pyridoxine administration with or without NT-3, animals stopped receiving pyridoxine but continued to receive vehicle or NT-3 for an additional $12 \mathrm{~d}$ to evaluate the longer-term effect of pyridoxine on sensory neurons. The inset shows that there was no difference between groups in the areas of cells that were $<1000 \mu \mathrm{m}^{2}$. However, there was a selective increase in area for cells that were $>1000 \mu \mathrm{m}^{2}$ in animals treated with pyridoxine + NT-3.

(Schaeppi and Krinke, 1985), and humans (Albin et al., 1987). In addition, pyridoxine produces clear and unambiguous behavioral, electrophysiological, and anatomical sequelae without producing general or systemic morbidity (Schaeppi and Krinke, 1982; Krinke et al., 1985; Montpetit et al., 1988; Xu et al., 1989). Such morbidity is a major problem in establishing a cisplatin neuropathy model in animals, in which the systemic toxicity of cisplatin makes the interpretation of behavioral or physiological measures more difficult (Tomiwa et al., 1986). Nonetheless, efficacy of NT-3 in a cisplatin-induced neuropathy in the rat has been reported (Gao et al., 1995).

In this series of experiments, we show that exogenous NT-3 protects proprioceptive neurons from pyridoxine-induced neurotoxicity. The effects of NT-3 were dose-dependent; daily doses of 5 and $20 \mathrm{mg} / \mathrm{kg}$ showed increasing neuroprotective effects, whereas in preliminary studies a daily dose of $2 \mathrm{mg} / \mathrm{kg}$ was without effect on any behavioral parameter. Functionally, rats cotreated with pyridoxine and NT-3 did not develop the signs of a large-fiber neuropathy (ataxia, gait dysfunction on irregular terrain, and areflexia) that were readily apparent with pyridoxine alone. We have used a battery of integrative sensory-motor tests to evaluate proprioceptive function affected by pyridoxine toxicity with or without NT-3 treatment. To assess the neurotoxicity of pyridoxine and the potential efficacy of NT-3, we chose behavioral tasks that depend on proprioceptive feedback during the performance of relatively natural behaviors. In one of these tasks, we used gait analysis to examine changes in the spatial parameters of simple overground locomotion. This quantitative assessment of foot-fall diagrams in rats is comparable to measures assessed in humans.
Although impairment in proprioception produces predictable alterations in the pattern of locomotion, similar to those we observed, other factors such as muscle weakness could generate similar patterns in the absence of any proprioceptive deficit. Therefore, we designed more sensitive assays to evaluate proprioceptive function by examining locomotion across a small cylindrical beam (precise locomotion) or across a complex open-grid runway. These tasks require a precise sensory feedback system for accurate paw placement.

The progression of impairments in simple overground and precise locomotion was largely arrested in pyridoxine-intoxicated rats treated with NT-3. For example, the gait pattern in rats given pyridoxine + vehicle was characterized by a broad base of support and small steps across a wide plank, classic signs of an ataxic gait. These changes are indicative of a common behavioral compensation mechanism to restore stability in response to the loss of position sense. In rats treated with NT-3, no change in the base of support was observed, although stride length and intrastep distance increased compared to baseline measures. This enhancement of gait parameters relates to behavioral conditioning, because similar alterations were observed in a pilot study examining the effects of long-term ( $28 \mathrm{~d}$ ) conditioning on control rats with or without NT-3.

The sensory-motor impairments produced by pyridoxine are consistent with a proprioceptive deficit, typical of a large-fiber sensory neuropathy. This conclusion is strongly supported by electrophysiological data showing that pyridoxine intoxication produced a remarkable decrement in $\mathrm{H}$ wave amplitude, whereas no change was observed in $\mathrm{M}$ wave amplitude. Such decrements in $\mathrm{H}$ wave amplitude, without marked loss of sensory conduction velocity, are supportive of pyridoxine producing a primary neuronal or axonal pathology, rather than a Schwann cell toxicity. Previous studies in rats have shown that pyridoxine exposure results in atrophy and death of DRG neurons and degeneration of their peripheral axonal processes (Krinke et al., 1985; Windebank et al., 1985). Anatomical analysis in the present study focused on the central projection of the primary afferents at the level of the dorsal columns. As predicted, in rats treated with pyridoxine alone we observed degeneration of ascending collaterals from primary afferent fibers. Although the constituent fiber type of the degenerating profiles was not delineated in this study, it is known that proprioceptive neurons (muscle and nonmuscle afferents) were included in this population. Pyridoxine treatment also produced morphological changes at the level of the neuronal cell body that were manifest as an apparent reduction in the number of large DRG neurons, although it remains unclear whether this represents frank cell loss or shrinkage of neurons. However, consistent with the correlation among the behavioral and electrophysiological findings, the morphological sequelae produced by pyridoxine were attenuated by NT-3 treatment.

In conclusion, we have shown by behavioral, electrophysiological, and anatomical measures that systemic administration of NT-3 in rats attenuates the large-fiber sensory neuropathy produced by pyridoxine.

\section{REFERENCES}

Airaksinen MS, Koltzenburg M, Lewin GR, Masu Y, Helbig C, Wolf E, Brem G, Toyka KV, Thoenen H, Meyer M (1996) Specific subtypes of cutaneous mechanoreceptors require neurotrophin-3 following peripheral target innervation. Neuron 16:287-295.

Albin RL, Albers JW, Greenberg HS, Townsend JB, Lynn RB, Burke Jr JM, Alessi AG (1987) Acute sensory neuropathy-neuronopathy from pyridoxine overdose. Neurology 37:1729-1732. 
Copray JCVM, Brouwer N (1994) Selective expression of neurotrophin-3 messenger RNA in muscle spindles of the rat. Neuroscience 63:1125-1135.

Davies AM, Lumsden AGS, Rohrer H (1987) Neural crest-derived proprioceptive neurons express nerve growth factor receptors but are not supported by nerve growth factor in culture. Neuroscience 20:37-46.

Desclin JC, Escubi J (1975) An additional silver impregnation method for demonstration of degenerating nerve cells and processes in the central nervous system. Brain Res 93:25-39.

DiStefano PS, Friedman B, Radziejewski C, Alexander C, Boland P, Schick CM, Lindsay RM, Wiegand SJ (1992) The neurotrophins BDNF, NT-3, and NGF display distinct patterns of retrograde axonal transport in peripheral and central neurons. Neuron 8:983-993.

Ernfors P, Lee K-F, Kucera J, Jaenisch R (1994) Lack of neurotrophin-3 leads to deficiencies in the peripheral nervous system and loss of limb proprioceptive afferents. Cell 77:503-512.

Friedman B, Scherer SS, Rudge JS, Helgren M, Morrisey D, McClain J, Wang D-Y, Wiegand SJ, Furth ME, Lindsay RM, Ip NY (1992) Regulation of ciliary neurotrophic factor expression in myelin-related Schwann cells in vivo. Neuron 9:295-305.

Gaese F, Kolbeck R, Barde Y-A (1994) Sensory ganglia require neurotrophin-3 early in development. Development 120:1613-1619.

Gao W-Q, Dybdal N, Shinsky N, Murnane A, Schmelzer C, Siegel M, Keller G, Hefti F, Phillips HS, Winslow JW (1995) Neurotrophin-3 reverses experimental cisplatin-induced peripheral sensory neuropathy. Ann Neurol 38:30-37.

Glass DJ, Yancopoulos GD (1993) The neurotrophins and their receptors. Trends Cell Biol 3:262-267.

Hamers FPT, Gispen WH, Neijt JP (1991) Neurotoxic side-effects of cisplatin. Eur J Cancer 27:372-376.

Hohn A, Leibrock J, Bailey K, Barde Y-A (1990) Identification and characterization of a novel member of the nerve growth factor/brainderived neurotrophic factor family. Nature 344:339-341.

Hory-Lee R, Russell M, Lindsay RM, Frank E (1993) Neurotrophin-3 supports the survival of developing muscle sensory neurons in culture. Proc Natl Acad Sci USA 90:2613-2617.

Jankowska E (1989) A neuronal system of movement control via muscle spindle secondaries. Prog Brain Res 299-303.

Klein R, Silos-Santiago I, Smeyne RJ, Lira SA, Brambilla R, Bryant S, Zhang L, Snider WD, Barbacid M (1994) Disruption of the neurotrophin-3 receptor gene trkC eliminates Ia muscle afferents and results in abnormal movements. Nature 368:249-251.

Krarup-Hansen A, Fugleholm K, Helweg-Larsen S, Hauge EN, Schmalbruch H, Trojaborg W, Krarup C (1993) Examination of distal involvement in cisplatin-induced neuropathy in man. Brain 116:1017-1041.

Krinke G, Naylor DC, Skorpil V (1985) Pyridoxine megavitaminosis: an analysis of the early changes induced with massive doses of vitamin B6 in rat primary sensory neurons. J Neuropathol Exp Neurol 44:117-129.
Kunkel-Bagden E, Bregman BS (1990) Spinal cord transplants enhance the recovery of locomotor function after spinal cord injury at birth. Exp Brain Res 81:25-34.

Legha SS (1986) Vincristine Neurotoxicity: pathophysiology and management. Med Toxicol 1:421-427.

Lindsay RM (1994) Neurotrophins and receptors. In: Progress in brain research (Seil FJ, ed), pp 3-14. New York: Elsevier.

Lindsay RM, Rohrer H (1985) Placodal sensory neurons in culture: nodose ganglion neurons are unresponsive to NGF, lack NGF receptors but are supported by a liver-derived neurotrophic factor. Dev Biol 112:30-48.

Lindsay RM, Wiegand SJ, Altar CA, DiStefano PS (1994) Neurotrophic factors: from molecule to man. Trends Neurosci 17:182-190.

Lipton RB, Apfel SC, Dutcher JP, Rosenberg R, Kaplan J, Berger A, Einzig AI, Wiernik P, Schaumburg HH (1989) Taxol produces a predominantly sensory neuropathy. Neurology 39:368-373.

Maisonpierre PC, Belluscio L, Friedman B, Alderson RF, Wiegand SJ, Furth ME, Lindsay RM, Yancopoulos GD (1990) NT-3, BDNF, and NGF in the developing rat nervous system: parallel as well as reciprocal patterns of expression. Neuron 5:501-509.

McMahon SB, Armanini MP, Ling LH, Phillips HS (1994) Expression and coexpression of trk receptors in subpopulations of adult primary sensory neurons projecting to identified peripheral targets. Neuron 12:1161-1171.

Montpetit VJA, Clapin DF, Tryphonas L, Dancea S (1988) Alteration of neuronal cytoskeletal organization in dorsal root ganglia associated with pyridoxine neurotoxicity. Acta Neuropathol 76:71-87.

Perot C, Almeida-Silveira MI (1993) The human H and T reflex methodologies applied to the rat. J Neurosci Methods 51:71-76.

Schaeppi U, Krinke G (1982) Pyridoxine neuropathy: correlation of functional tests and neuropathology in beagle dogs treated with large doses of vitamin B6. Agents Actions 12:575-582.

Schaumburg H, Kaplan J, Windebank A, Vick N, Rasmus S, Pleasure D, Brown MJ (1983) Sensory neuropathy from pyridoxine abuse: a new megavitamin syndrome. N Engl J Med 309:445-448.

Tomiwa K, Nolan C, Cavanagh JB (1986) The effects of cisplatin on rat spinal ganglia: a study by light and electron microscopy and by morphometry. Acta Neuropathol (Berl) 69:295-308.

Windebank AJ, Low PA, Blexrud MD, Schmelzer JD, Schaumburg HH (1985) Pyridoxine neuropathy in rats: specific degeneration of sensory axons. Neurology 35:1617-1622.

Xu Y, Sladky JT, Brown MJ (1989) Dose-dependent expression of neuronopathy after experimental pyridoxine intoxication. Neurology 39:1077-1083.

Zhou X-F, Rush RA (1995) Sympathetic neurons on neonatal rats require endogenous neurotrophin-3 for survival. $J$ Neurosci 15: $6521-6530$. 